\title{
Study on the Maturity Evaluation System of the County Economy Cooperative Development
}

\author{
Su Zhang \\ School of Economics and Management, Changchun University of Science and Technology \\ Changchun 130022, China \\ E-mail: zhangsu1972@163.com
}

\begin{abstract}
It is a systematic project to evaluation the cooperative development of certain county economy. Based on the meanings of the county economy cooperative development, the maturity of the county economy cooperative development based on the recycle economy is introduced, and the principles to establish the maturity evaluation index system of the county economy cooperative development are proposed, and a reasonable evaluation index system is established in the article.
\end{abstract}

Keywords: County economy, Cooperation, Maturity

\section{Meanings of the county economy cooperative development}

Since reforming and opening up, the local economic and social developments in China have achieved great achievements, and people's living levels in various regions have been largely improved. However, the problem of the inconsistent regional developments is more and more prominent, and the gap of the GDP per capita among regions are expanding, and so is the gap of the public service levels enjoyed by different regions. If the situation continually develops, it is hard to ensure the harmony of the society, the stability of the politics and the sustainable development of the economy, and the historical mission to build a well-off society in an all-round way will not be completed, so it is important and urgent to improve the harmonious development among regions.

The regional harmonious development has not been defined scientifically and admittedly up to the present, and its concept should be studied comprehensively. To describe the good mutual relationships among factors in the system, some scholars thought that the original meaning of the harmony was "to harmonize identically and cooperate expediently". That was the early description and definition about the harmony in China, and it only proposed and emphasized the interior harmony in the system. Subsequently, other scholars developed its meaning, and they took the region as a PRED system, and pointed out that the harmony should mainly describe the situation about mutual function and cooperation among systems, and begun to pay attention to the association between the harmony and the system. At the same time, there were other scholars who begun to study the harmony in another meaning, i.e. to realize the mutual development by establishing the cooperative relationships among regions, which emphasized the association and good cooperation among regions, so the regional harmonious development begun to be understood and defined more completely and broadly, but the relative studies have not be developed in an all-round way.

Making a comprehensive view on scholars' discussions about the definition of the regional harmonious development, the course of the study about the regional economy cooperative development can be simply summarized. It extended from the harmony among counties (or systems) to the harmony between interiors and exteriors and to the emphasized exterior harmony, and this course is consistent with the direction of the economic development, and shows obvious feature of stage and development tendency. In the day that the economy develops quickly, the harmony among interiors and exteriors of the county is very important for the development. The meaning of the county economy cooperative development should be generalized, and the word of "harmony" in existing researches often occurred with "reducing the regional gap", and with the continual development of the economy, the researches about the competition and cooperation among counties, the county cooperation, the county association, the county integration will enrich and develop the meanings and connotation of the harmony, so if one of above concepts is understood as the definition of the county economy cooperative development, it will take a part for the whole, and in existing researches, above words were often crossing to be used, which shows that different scholars would differently understand the county economy based on different development bases, and all above concepts will be listed in the category of the county economy cooperative development (Wang, 2006, P.125-138).

Thus it can be seen that the county economy cooperative development can be defined by the interior harmony of the 
county and the exterior intergrowth of the county. The county economy cooperative development integrates the whole feature, the inherence and the comprehensive feature to form an organic integer with mutual cooperation and improvement in the interior of the county, and create optimal total benefit by good competition and close cooperation, and form the sustainable development situation including economy, society, culture and ecology with mutual supplements of advantages and linkages, and achieve a kind of super stage with highly harmonious development in the interior and exterior of the county.

\section{The maturity of the country economy cooperative development based on the recycle economy}

As viewed from the influences of the resource flow and the economic growth on the resources and environment, the growth pattern has two modes. One mode is the traditional mode, i.e. the single-directional beeline process of "resources-products-castoffs", under which mode more resources are consumed, the negative influences on the resources and environment are larger. The other mode is the feedback-recycle process of "resources-products-castoffs-renewable resources", which can more effectively utilize the resources and protect the environment, and acquire possible large economic benefits and social benefits by possible small resource consumption. Generally speaking, the recycle economy takes the highly effective utilization and recycle utilization of resources as the core, and takes "reduction, recycle and resources" as the principles, and it is the essential reform of the traditional growth mode with "mass production, mass consumption and mass disuse" (Wu, 2005, P.9-198).

The recycle economy is a new development concept, and it embodies the development direction of the environment protection, reflects the essential contents of the sustainable development, and is the guarantee to realize the county economy cooperative development (Qing, 2006, P.119-127), which is embodied in following aspects.

(1) The recycle use of resources can ensure the developments of the economy and the society.

To guarantee the developments of the economy and the society is the basic principle to realize the industrial cooperative development of the county economy. Before the knowledge economy is realized, the utilization of natural resources still is the decisive factor of the economic development. Starting form the concept of big system analysis, the recycle economy controls the gross to solve the problem of resource shortage by the resource recycle, which is the best method obviously.

(2) The recycle economy guarantees the cooperative development of economy, society, environment and ecology.

The cooperative development of economy, society, environment and ecology is the basic principle to realize the industrial cooperative development of the county economy. The recycle economy minimizes the discharge of castoffs to furthest protect the environment. Starting from the opinion of the balance of the ecological system, the recycle economy intervenes in the ecological system as little as possible to protect the balance of the ecological system, and it reduces the developments of natural resources and maintains it in the carrying capacity of the ecological system. At the same time, the recycle economy takes the ecological construction as the infrastructure construction to largely promote the harmonious development of economy and ecology.

(3) The recycle economy guarantees the generation balance of the resource utilization.

The principle followed by the recycle economy is to utilize the renewable resources as more as possible, guarantee the renewable ability of the renewable resources, leave more renewable resources for next generation, and realize the generation balance of the resource utilization.

(4) The recycle economy can promote the regional cooperative development in the region.

When the industrialization is completed, the difference of the possession of natural resources will be most important factor to influence the balance of the regional development. The recycle economy advocates the recycle utilization of resources, so it can largely reduce the unbalance of regional development induced by the difference of the possession of natural resources. In the production, the recycle economy utilizes the principle of high science and technology as more as possible to eliminate the regional differences. From above two aspects, the recycle economy can promote eliminating the poverty with deficient resources.

In above analysis, when human production mainly depends on the utilization of natural resources, the guarantee to realize the industrial cooperative development of county economy is to largely develop the recycle economy.

\section{Principles to establish the maturity evaluation index system of the county economy cooperative development}

To establish the maturity evaluation index system of the county economy cooperative development, following principles should be followed.

\subsection{Principle of identical target}

First, the evaluated objects and evaluation target should be confirmed, and the evaluation target is mainly embodied by the evaluation system, so it must ensure the identity of the evaluation system and the evaluation target. 


\subsection{Principle of science}

To establish the index system should persist in the principle of science. Following the rule of affair development can help to apply modern scientific management technology to ensure the reasonability of the content and structure of the index system.

\subsection{Principle of combining the complete feature with the pertinence}

When selecting evaluation indexes, except that comprehensively considering the research target and the functions of different indexes, the basic character of the industry and the basic natural conditions about the existence and development should be reviewed also. For any one industry, the basic conditions of its existence and development depend on the investment guarantee, the output efficiency and the market acceptation ability. Therefore, to evaluate the regional industry, the establishment of relative indexes should reflect not only the basic character of the regional industry, but also the basic conditions of the existence and development of regional industry.

\subsection{Principle of validity and principle of feasibility}

When following the complete feature, the establishment of the index system should not pursue perfection and exaction, but pursue simple and effective. Those indexes which don't influence the target evaluation largely or don't show difference among evaluated objects should be deleted. Except for that, the establishment of the index system should start from the practice and combine demand with possibility, i.e. accord with the principle of validity and principle of feasibility. For the selection and evaluation of the regional industry, there are so many side-statistical data should be studied, but for some indexes, the relative data in real statistical materials can not be collect or exist. Therefore, starting from practical situation, this article can only collect relative data and materials from various yearbooks issued publicly to establish the index system of the regional industry evaluation.

\subsection{Principle of independence}

The indexes on the same level in the index system should be independent each other, which can ensure that same target can not be computed repeatedly, and the independence of each index is the premise of various weight methods. But the relationships among different indexes can be affiliation, and can be dependent (Li, 2003).

\section{The maturity evaluation index system of the county economy cooperative development}

According to the idea of the multilevel hierarchical structure of the big system, as the big social economic system, Chinese county economy is an organic integer including society, economy, science and technology, and environment, and taking human activities as the center. Except for general characters of the big system such as large scale, complex structure, comprehensive function and numerous factors, it still has its own characters and possesses obvious opening feature. Figure 1 is the sketch map of its structure.

As seen in Figure 1, the low level (the first level) is the local control level of various subsystems (society, economy, science and technology, environment) in the big system of county economy, and it directly controls various controlled factors (i.e. the indexes in various subsystems in the cooperative development evaluation index system) in the subsystems. The middle level (the second level) is the hierarchical cooperative development control level, which uses the cooperative control model to analyze the associations among various subsystems, controls cooperatively various subsystems by the optimal measure, and offers the optimal strategic schemes and comprehensive data information for the cooperative development. The super level (the third level) is the comprehensive evaluation control level, which establishes corresponding comprehensive indexes and implementation schemes by the hierarchical structure and cooperative development index model to realize the total target of the county industrial cooperative development. These three hierarchical control levels are integrated each other, and they can put forward corresponding industrial cooperative development evaluation index system through qualitative analysis (including the policies and guidelines of the party and government, the social development theory, leaders and experts' opinions), establish a set of practical method, and compute concrete result by proper quantitative model description.

In recent years, for the research about the cooperative development and the cooperative development strategy of various subsystems in the social economic system in China, the "four-division method (the cooperative development of economy, science and technology, society and environment)" was generally adopted, which highly emphasized the basic natural and material status of the ecological environment in the modernization construction. According to the basic ideas that the economy is the base, the science and technology is the power, and the environment is the guarantee, and the principles of science, simple and system, various indexes matching with the county economy development are selected to design the index system of the county economy cooperative development.

\subsection{The subsystem of society}

(1) The total population $\left(\mathrm{X}_{1}^{1}\right)$ : it is the index to reflect the total amount of the population in the county;

(2) The proportion of the rural population in the total employment population $\left(\mathrm{X}^{2}{ }_{1}\right)$ : it reflects the employment situation 
of rural farmers;

(3) The bed capacity of social welfare homes per ten thousand people $\left(\mathrm{X}^{3}{ }_{1}\right)$ : it reflects the social welfare condition and level;

(4) The bed capacity of hospitals and health centers per ten thousand people $\left(\mathrm{X}^{4}\right)$ : it reflects the medical condition and level;

(5) The telephone popularization rate $\left(\mathrm{X}_{1}^{5}\right)$;

(6) The year-end unit employment number $\left(X_{1}^{6}\right)$;

(7) The total power of rural mechanisms $\left(\mathrm{X}_{1}^{7}\right)$.

4.2 The subsystem of economy

(1) The balance of the rural and urban resident savings $\left(\mathrm{X}_{2}{ }_{2}\right)$ : it reflects the index of savings of rural and urban residents;

(2) The far products offered by ten thousands farm people $\left(\mathrm{X}_{2}^{2}\right)$ : it reflects the marketization degree of farm products and the development degree of the rural market economy;

(3) The scale-above gross industrial output (present price) $\left(\mathrm{X}_{2}^{3}\right)$ : it reflects the development situation of scale-above enterprises, and it is the important index that the social production develops to depth and extent;

(4) The balances of various loans of the financial institutions in the year-end $\left(\mathrm{X}_{2}^{4}\right)$ : it is the important index to reflect the investment situation;

(5) The accomplishment amount of the fixed asset investment $\left(\mathrm{X}_{2}^{5}\right)$ : it is the important index to reflect the after effects of the county economy and the social development;

(6) The local finance payout $\left(\mathrm{X}_{2}^{6}\right)$ : it is the important index to reflect the payout degree of the county economy;

(7) The first industrial increment $\left(\mathrm{X}_{2}^{7}\right)$ : it is the important index to reflect the development of the first industry;

(8) The second industrial increment $\left(\mathrm{X}_{2}^{8}\right)$ : it is the important index to reflect the development of the second industry.

4.3 The subsystem of science and technology

(1) The scale-above industrial amount per ten thousand people $\left(\mathrm{X}_{3}^{1}\right)$ : it is the important index to reflect the population quality of science-technology;

(2) The student amount in common high schools per ten thousand people $\left(\mathrm{X}_{3}^{2}\right)$ : it is the important index to reflect the population quality of culture;

(3) The student amount in common schools per ten thousand people $\left(\mathrm{X}_{3}^{3}\right)$ : it is the important index to reflect the popularization degree of the basic education;

(4) The trading quantum of the technical market per capita $\left(\mathrm{X}_{3}^{4}\right)$ : it is the important index to reflect the marketization of the technology;

(5) The proportion of the science-technology payout in the local finance payout $\left(\mathrm{X}_{3}^{5}\right)$ : it is the important index to reflect the investment degrees in education, science-technology and culture.

\subsection{The subsystem of environment}

(1) The target hitting rate of the industrial waste water disposal and discharge $\left(\mathrm{X}_{4}^{1}\right)$;

(2) The disposal rate of industrial waste gas $\left(\mathrm{X}^{2}{ }_{4}\right)$;

(3) The comprehensive utilization rate of industrial solid wastes $\left(\mathrm{X}_{4}^{3}\right)$;

(4) The using rate of green resources $\left(\mathrm{X}_{4}^{4}\right)$ : it reflects the recycle feature of the resource utilization (Wang, 2006).

Above four indexes reflect the degree of economic development to the environment pollution and the ability of the development of environment protection science and industry to the pollution treatment.

\section{References}

Li, Peng. (2003). Study on the Cooperative Development of County Economy. Beijing: Economic Management Press. Oct of 2003.

Qing, Lidong. (2006). Study on the County Cooperative Development. Beijing: CPC Central Party School Press. P.119-127.

Wang, Chuanmin. (2006). Study on the County Economy Industrial Development Mode. Beijing: China Economy Press. P.125-138.

Wang, Chuanmin. (2006). Study on the Industrial Cooperative Development of County Economy. Beijing: Doctor's 
Thesis of Beijing Jiaotong University.

Wu, Jisong. (2005). New Recycle Economics. Beijing: Tsinghua University Press. P.9-198.

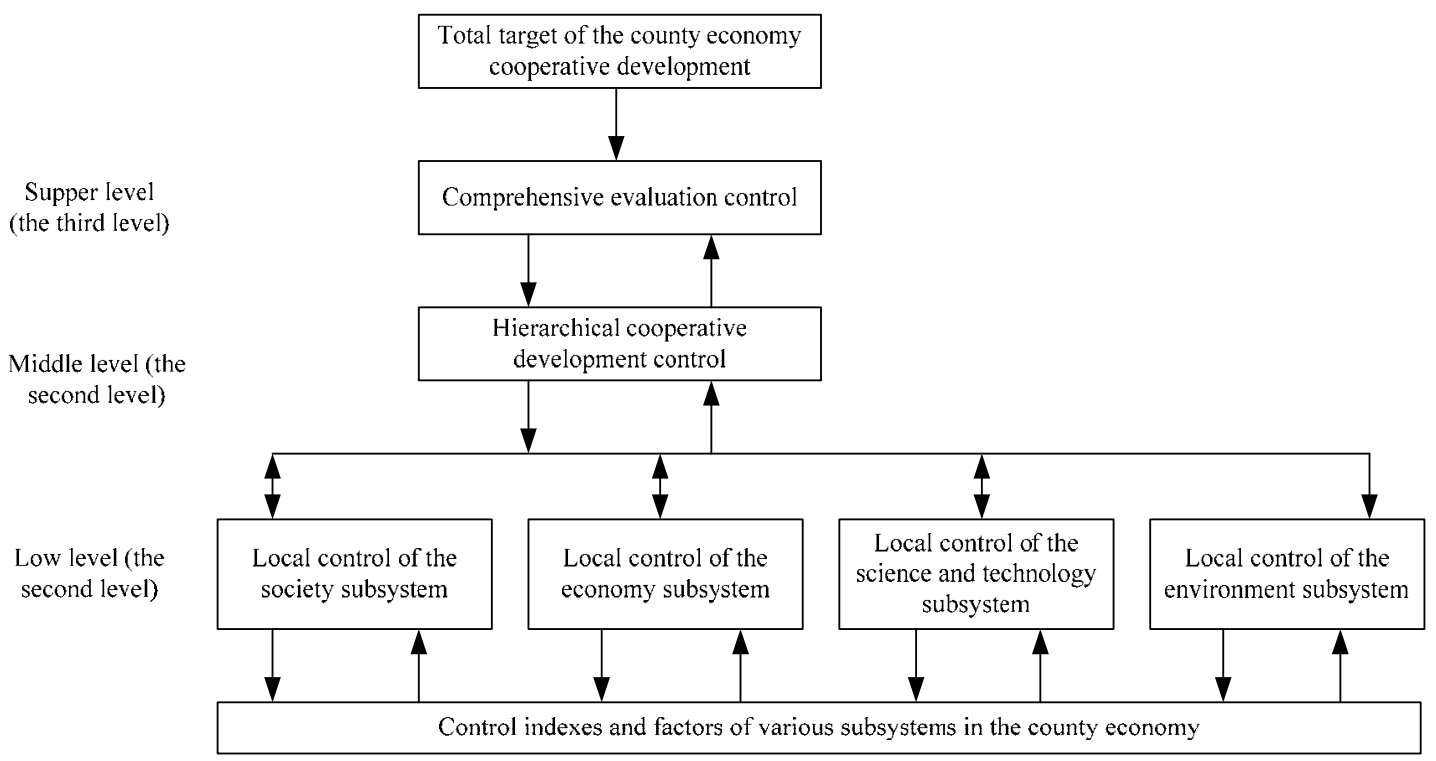

Figure 1. Multilevel Hierarchical Structure of the County Economy Cooperative Development 